\title{
Measuring Nutrition Literacy: Problems and Potential Solutions
}

\author{
Elena T Carbone* and Heather D Gibbs \\ Department of Nutrition, Chenoweth Lab,100 Holdsworth Way, Amherst, MA 01003, USA
}

Health literacy is defined as the "degree to which individuals have the capacity to obtain, process, and understand basic health information and services needed to make appropriate health decisions" [1]. Health literacy skills encompass a wide range of components: reading and writing (print literacy), speaking and listening (oral/aural literacy), numeracy (use of numbers), and cultural and conceptual knowledge [2]. Health literacy is one of the most important crosscutting issues to affect health in the US [2]. Indeed, it is a stronger predictor of a person's health than age, income, employment status, education level, and race [3]. Poor health literacy affects all levels of the health care experience. It impedes provider-patient communications, and affects the ability to access and navigate the health service system [2]. The readability of health information is also of concern. More than 90 million adults in the US have limited ability to use print materials to accomplish everyday tasks. Most adults read at an eighth-grade level and $20 \%$ read at or below a fifth-grade level [4,5], yet many health education materials are written at a ninth-grade level or above [6]. If this disparity is not addressed, providers will be unable to respond adequately to growing global health concerns such as obesity, diabetes, heart disease, and cancer [7].

Understanding the importance of nutrition and healthful dietary behaviors is critical to the prevention and management of each of these global health concerns. Data suggest that literacy is a key factor accounting for differences in dietary habits [8], with more-healthful eating practices positively associated with higher nutrition literacy skills [9]. Consequently, the construct of nutrition literacy has been introduced to identify the degree to which individuals can obtain, process, and understand the basic nutrition information and services they need to make appropriate nutrition decisions [9].

Although it has grown rapidly, the field of health literacy is still relatively new and discussions are ongoing about the construct and its measurement [10]. No comprehensive measure exist that captures the full spectrum of skills and knowledge associated with health literacy. In addition, most health literacy research does not explicitly focus on food or nutrition, and dietetics practitioners often remain unaware of patients' health literacy level [11]. It is therefore not surprising that non-validated measures of nutrition literacy exist.

The purpose of this commentary is to briefly review a selection of commonly-used measures of health literacy and to introduce the need for a nutrition-specific assessment.

Numerous health literacy assessments are available, but each has limitations. Two of the more commonly used tools are the Rapid Estimate of Adult Health Literacy in Medicine (REALM) [12] and the Test of Functional Health Literacy in Adults (TOFHLA) [13]. Both identify print literacy in the context of health care; TOFHLA also measures numeracy. A relatively new addition, the Newest Vital Sign (NVS) [14], also measures both literacy and numeracy and requires only three minutes to administer. Although the NVS uses a food label in its assessment, it is not described as a measure of nutrition literacy, but rather of health literacy [14]. Therefore, while each of these instruments can reliably identify individuals with limited health literacy skills, none are specific to measuring nutrition literacy per se. The only known assessment specific to nutrition is the Nutritional Literacy Scale by Diamond [15]. This untimed 28-item reading comprehension assessment was developed as a research tool to measure adults' ability to understand nutrition information. It has good internal consistency (Cronbach's alpha coefficient of 0.84 ) and construct validity (Pearson correlation $=0.61$ ) compared with the reading comprehension score in the Short Test of Functional Health Literacy in Adults (S-TOFHLA) [16]. However, the instrument itself is not published and has not been used or discussed further in literature.

Little is known regarding general knowledge of nutrition principles and "how to" knowledge; assumptions therefore cannot be made regarding nutrition literacy proficiencies in the general population, nor in individuals. The responsibility of identifying deficits in food and nutrition knowledge rests with the nutrition professional as a part of the nutrition assessment, the first step in the Nutrition Care Process and Model [17]. An instrument designed to identify nutrition literacy could provide objective support for such an assessment.

Instrument design is a time-consuming, and thereby costly, process. However, with increasing national attention to the importance of literacy in the health care, and ongoing attention and funding devoted to measurement development, it is hopeful that progress will be made. Development of a nutrition literacy measure will be significant because it will formalize attempts made by nutrition professionals to assess educational readiness of clients, improving delivery of nutrition education, and thereby improve their nutritional status and health.

More research is expected to emerge as the importance of health and nutrition literacy is further recognized by health care practitioners. In the meantime, numerous health literacy measures exist that have utility in the context of dietetics; therefore, use of these validated measures is encouraged as a means of assessing the health literacy levels of patients and clients.

Recognizing and addressing problems of low nutrition literacy skills early has potential to reduce long-term negative health outcomes. Low nutrition literacy is a societal issue which, if successfully addressed, may also help reduce health disparities. Future research using a communitybased approach to develop and test a nutrition literacy measure that is informed by the target audience will further build needed nutrition literacy skills among low income, multiethnic audiences.

For a more comprehensive discussion of health literacy measures, the report published by the National Academies Press can be referred [2].

\section{References}

1. Selden CR, Zorn M, Ratzan SC, Parker RM (2000) Health literacy (CBM20001). Current bibliographies in medicine $2000-1$.

*Corresponding author: Dr. Elena $\mathrm{T}$ Carbone, Department of Nutrition, Chenoweth Lab,100 Holdsworth Way, Amherst, MA 01003, USA, Tel: 413-5451071; Fax: 413-545-1074; E-mail: ecarbone@nutrition.umass.edu

Received November 26, 2012; Accepted November 26, 2012; Published November 28, 2012

Citation: Carbone ET, Gibbs HD (2013) Measuring Nutrition Literacy: Problems and Potential Solutions. J Nutr Disorders Ther 3:e105. doi:10.4172/21610509.1000e105

Copyright: (C) 2013 Carbone ET. This is an open-access article distributed under the terms of the Creative Commons Attribution License, which permits unrestricted use, distribution, and reproduction in any medium, provided the original author and source are credited. 
2. Nielsen-Bohlman L, Panzer AM, Kindig DA, eds (2004) Health Literacy: A Prescription to End Confusion. Washington, DC: National Academies Press, Washington DC.

3. American Medical Association (1999) Health literacy: report of the Council on Scientific Affairs. Ad Hoc Committee on Health Literacy for the Council on Scientific Affairs, American Medical Association. JAMA 281: 552-557.

4. Kirsch IS (2001) The International Adult Literacy Survey (IALS): Understanding What Was Measured. Princeton, NJ: Educational Testing Service.

5. Kirsch IS, Jungeblut A, Jenkins L, Kolstad A (1993) Adult Literacy in America: A First Look at the Results of the National Adult Literacy Survey. Washington, DC: National Center for Education Statistics, Educational Testing Service.

6. Hill-Briggs F, Smith AS (2008) Evaluation of diabetes and cardiovascular disease print patient education materials for use with low-health literate populations. Diabetes Care 31: 667-671.

7. Carmona RH (2006) Health literacy: A national priority. J Gen Intern Med 21 803

8. Silk KJ, Sherry J, Winn B, Keesecker N, Horodynski MA, et al. (2008) Increasing nutrition literacy: testing the effectiveness of print, web site, and game modalities. J Nutr Educ Behav 40: 3-10.

9. Lino M, Basiotis PP, Anand RS, Variyam JN (1998) The diet quality of Americans: Strong link with nutritional knowledge. Nutrition Insights.
10. Baker DW (2006) The meaning and the measure of health literacy. J Gen Intern Med 21: 878-883.

11. Carbone ET, Zoellner JM (2012) Nutrition and health literacy: a systematic review to inform nutrition research and practice. J Acad Nutr Diet 112: 254-265.

12. Davis TC, Long SW, Jackson RH, Mayeaux EJ, George RB, et al. (1993) Rapid estimate of adult literacy in medicine: a shortened screening instrument. Fam Med 25: 391-395.

13. Parker RM, Baker DW, Williams MV, Nurss JR (1995) The test of functional health literacy in adults: a new instrument for measuring patients' literacy skills. J Gen Intern Med 10: 537-541.

14. Weiss BD, Mays MZ, Martz W, Castro KM, DeWalt DA, et al. (2005) Quick assessment of literacy in primary care: the newest vital sign. Ann Fam Med 3: $514-522$.

15. Diamond JJ (2007) Development of a reliable and construct valid measure of nutritional literacy in adults. Nutr J 6: 5 .

16. Baker DW, Williams MV, Parker RM, Gazmararian JA, Nurss J (1999) Development of a brief test to measure functional health literacy. Patient Educ Couns 38: 33-42.

17. Lacey K, Pritchett E (2003) Nutrition Care Process and Model: ADA adopts road map to quality care and outcomes management. J Am Diet Assoc 103 1061-1072. 